\title{
A PERFORMANCE EVALUATION OF A MULTIFACETED ELECTRONIC VOTING FRAMEWORK
}

\author{
Oladotun O. OKEDIRAN \\ Department of Computer Science and Engineering, Faculty of Engineering and Technology, \\ Ladoke Akintola University of Technology, Ogbomoso, Nigeria, e-mail: oookediran@lautech.edu.ng
}

\begin{abstract}
This paper, we present a performance evaluation of a multifaceted electronic voting framework. The electronic voting model that was developed on the framework is capable of handling electronic ballots with multiple scopes simultaneously via three different electronic voting means. The model catered for probity of an election process in terms of generic and functional requirements. The performance evaluation detailed the degree to which the framework meets the generic and functional requirements of electronic voting systems using a five-point psychometric scale. The results of the quantitative analysis showed that the framework is capable of ensuring voters' privacy and authenticity while the integrity, accuracy and verifiability of ballots casted are guaranteed.
\end{abstract}

Keywords: e-voting, framework, privacy, authenticity, integrity, security, verifiability

\section{INTRODUCTION}

Voting and elections are essential components of any democratic process. Unlike any other transactional event, the result of elections can have consequential effects on the wellbeing of any society. Recent elections have seen a gradual decline in the overall percentage of the electorate exercising their right to vote [14]. This is worrisome from a democratic point of view in that, if the reasons of the decline are left unchecked, the mandate of those elected to hold the positions might eventually be questionable. This decline in public participation in elections is largely and generally attributed to lack of trust in most electioneering processes and more specifically, the voting system [11].

The challenge of developing an acceptable voting system that can reduce the manipulation and falsification of election results has been a major issue world over. Many conventional voting techniques that include traditional paper ballots, mechanical devices, or electronic ballots have been employed over the years in elections. Each of these techniques had attendant short comings. Gross manipulations, abuse and irregularities often trail elections conducted using these systems of voting $[3 ; 8 ; 9 ; 10 ; 11]$. Furthermore, the cost and process of these conventional voting systems are both increasing geometrically and tedious to execute [6]. With advancement in information and telecommunications technologies, e-voting is emerging as a significant alternative to these conventional systems.

Exhaustive studies have shown that electronic voting, if carefully designed, guarantees the freedom to vote, secrecy of the vote, non modification of the expressed intention of the voter, lack of intimidation during the voting operation, enhances polling and votes' security, confidentiality, sincerity and increased cost savings on reduced manpower, logistical materials and tools; and above all instant analysis and reporting [12].

In this paper, a quantitative performance evaluation of a multifaceted electronic voting framework proposed in the work of [12] is presented using a psychometric analysis. Users of acceptable voting age were asked to use the developed electronic voting model that evolved from the framework. Relevant data were captured and analyzed using descriptive data analysis in Statistical Package for Social Sciences (SPSS) with the intent of asserting the degree to which the e-voting framework fulfilled generic, functional and social security requirements for the conduct of credible, free and fair e-elections. The rest of the paper is organized into the following: Section two describes the basic design requirements for e-voting systems; Section three describes methodologies adopted to carry out the research; Section four presents the results and discussion of the quantitative assessments and Sections five concludes and provide the gap intended to fill the future.

\section{DESIGN REQUIREMENTS FOR E-VOTING SYSTEMS}

The design of any voting system, whether electronic or manual, must satisfy a number of sometimes competing criteria. Of utmost importance are the requirements for accuracy, privacy, security, authenticity, democracy and verifiability. The anonymity of a voter's ballot must be preserved, both to guarantee the voter's safety when voting against a malevolent candidate, and to guarantee that voters have no evidence that proves which candidates received their votes [13]. The existence of such evidence would allow votes to be purchased by a candidate. The voting system must also be tamper-resistant to thwart a wide range of attacks, including ballot stuffing by voters and incorrect tallying by insiders. Another factor, of immense importance is the "human usable" by the entire voting population, regardless of age, infirmity, or disability. Providing accessibility to such a diverse population is an important engineering problem and one where, if other security is done well, electronic voting could be a great improvement over current paper systems. Flaws in any of these aspects of a voting system, however, can lead to indecisive or incorrect election results [13].

[1] recommended that e-voting systems should guarantee the following major principles of democratic elections:

$\begin{aligned} \text { i. } & \text { Direct suffrage } \\ \text { ii. } & \text { Universal } \\ \text { iii. } & \text { Equal } \\ \text { iv. } & \text { Free } \\ \text { v. } & \text { Secret }\end{aligned}$


In addition to the aforementioned principles above, [2] and [7] proposed that any electronic voting system should have the following core properties:

i. Privacy: After casting a vote, no one should be able to link the voter to this vote;

ii. Authenticity: Only eligible voters can cast their votes;

iii. Accuracy: Once a voter cast a vote, no alternation to this vote is permitted. Moreover, All valid votes must be counted, whereas all invalid votes must not be discarded;

iv. Integrity: Throughout the voting process, a vote can't be tampered with;

v. Democracy: All eligible voters must be able to vote, one person - one vote and no one can vote more than once or vote for others.

vi. Verifiability: Voters can independently verify that their votes have been counted correctly and are included in the final tally.

\section{MATERIALS AND METHODS}

In this section, an apt description of the model architectural design, performance assessment factors, research questions, data collection method and tools for data analysis were discussed.

\subsection{Framework and Model Design}

The requirements definition of the multifaceted evoting framework presented in the work of [11] and depicted in Figure 1, is the same as those presented in Section 2. The system specific requirements catered for within the framework are:

The system-specific requirements of the framework allow:

i. Multi-user: A number of voters can vote simultaneously;

ii. Accessibility: The system can be accessed by voters from any location using secure Internet and/or mobile devices;

iii. Availability: The system must have highavailability during an election campaign.

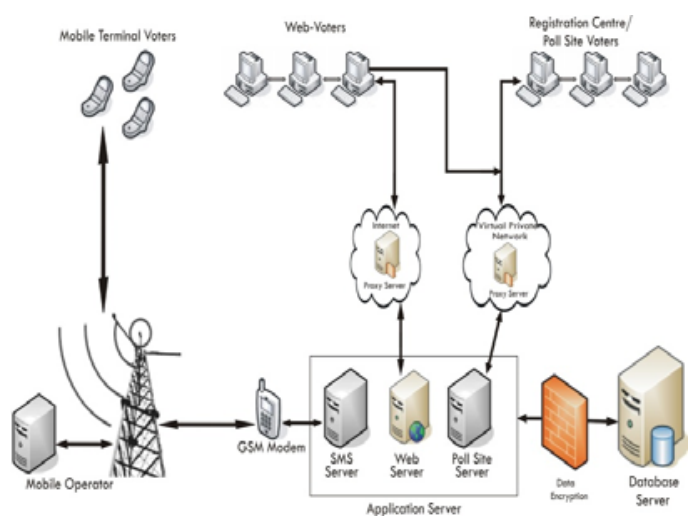

Fig. 1 Architectural Framework of the Multifaceted Evoting System (Source: [11])
The architecture defines the key components of the framework together with the interactions between these components. The overall functional structure of the framework is summarised as follows: an eligible electorate (18 years and above) registers with the electoral body at a gazetted registration centre. The person identifies self by providing all the required biodata, phone number and the fingerprints of the person will be scanned and stored in the database. The registered electorate will be given a unique voter identification number and a unique voting code which he/she is expected to keep confidential.

A remote internet voter (client) runs the Uniform Resource Locator (URL) for the e-voting system through a web browser. The web application prompts the voter to download the voting application package that should be installed on the voter's computer. The voting application runs remotely on the client's computer. Voting is done via the voting application installed on the client's computer by selecting the political party of choice and a fingerprint scan. A remote mobile terminal voter votes via SMS. Poll site voters cast their electronic ballots at designated Poll sites. The voter selects the political party he/she wants to vote for on the voting interface and scans a fingerprint to cast the vote. The developed e-voting system was designed to allow many voters to voting simultaneously while ensuring highly availability during the electioneering process. Authentication into the voting system is either by biometrics or voter identification number (voter ID) and voting code generated for each voter after registration. Poll site voting and internet voting requires a fingerprint scan for ballot casting while SMS voting requires combination of mobile number (SIM) of the electorate, the generated voter ID and voting code, which are unique for voter. A voter ID and voting code sent to a particular SIM after registration cannot be used on another SIM for voting. The security considerations of the system were based on a RSA encryption algorithm which was implemented to secure end to end messaging, the Transport Layer Security (SSL/TLS) which is a VPNs' cryptographic tunneling protocol and firewalls in form of proxy servers. Furthermore, the web server only hosts the web page of the e-voting system. Actual ballots casted by web voters are sent to the Poll site server which is on a VPN. Ballot casted are record in the data tables at the backend of the database as binary templates. The evolving ensures only one-person, one-vote (democracy) property of voting systems. The voter's fingerprint, voter's SIM, voting ID and voting codes of a voter intending to cast his/her ballot are matched at every voting attempt to prevent multiple voting. Figure 2 depicts the e-voting model evolved from the framework.

The overall system was developed base on the derived system requirements and on the .NET framework using Visual C\#, GrFinger SDK (version 4.2) and Ozeki message server (version 6).Web applications were developed using ASP. NET while the data tables at the backend in the database server were developed using MS SQL Server 2008. Figures 3-5 depict the some menus evolved from the implementation of the e-voting model. 


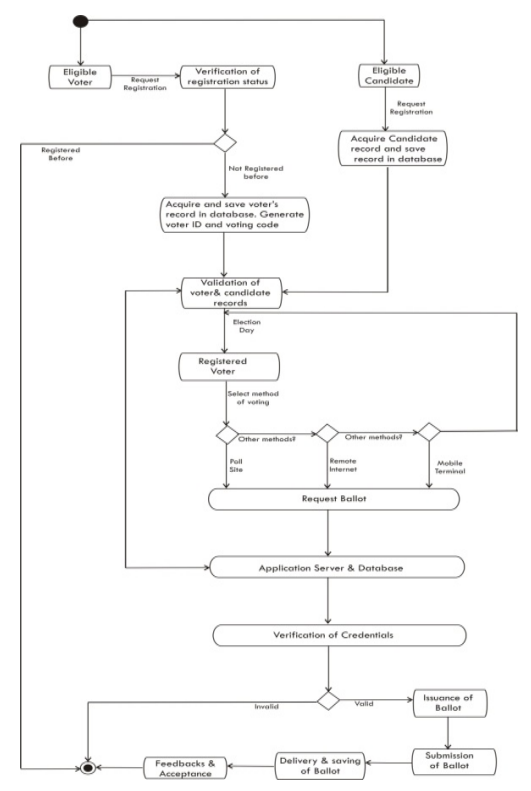

Fig. 2 E-voting Model Evolved from the Framework

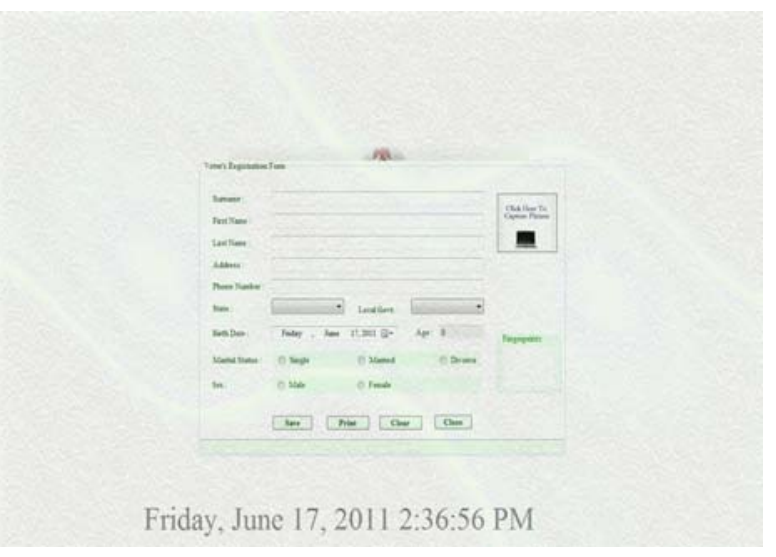

Fig. 3 Voters' Registration Interface of the E-voting Model

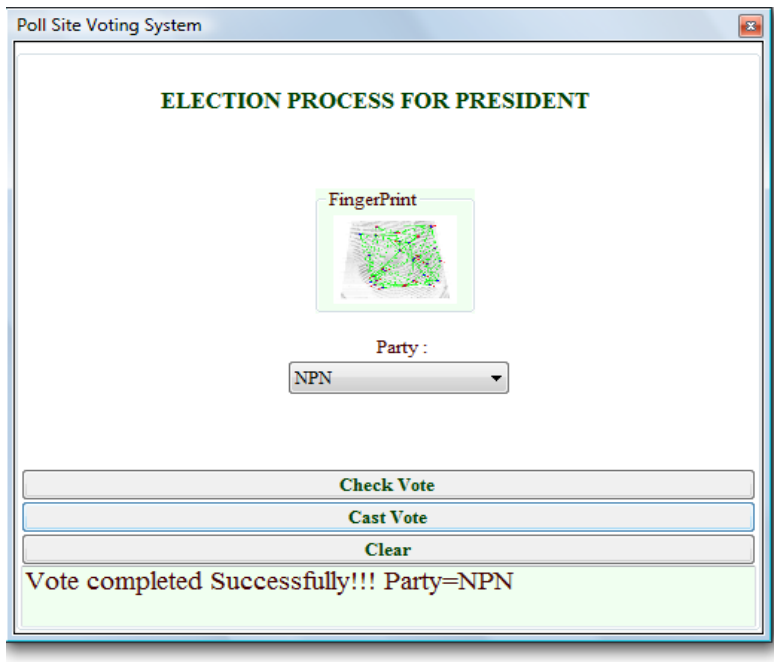

Fig. 4 Poll Site Voting Interface of the E-voting Model

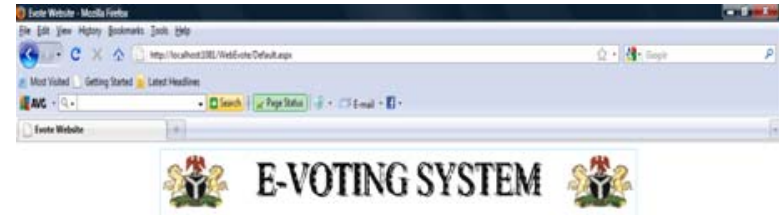

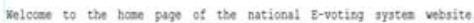

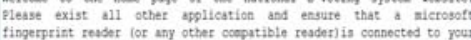
systea. Download Setup
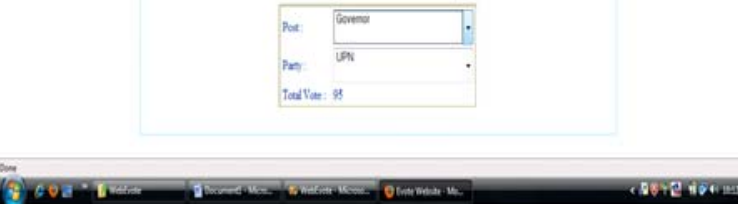

Fig. 5 Internet Voting Interface of the E-voting Model

\subsection{Research Questions}

The generic requirement of the e-voting model that evolved from the framework was based on the criteria mentioned in Section 2. Users perception of the developed system were collected after experimental using a psychometric scale commonly used in questionnaires to ascertain if the core values desired in any voting system whether manual or electronic are inherent in the developed e-voting model. The following questions bothering on whether the developed e-voting model fulfilled the generic requirements desirable in voting systems were raised in the questionnaire administered:

i. Can votes casted remain unaltered? Requirement for "Integrity".

ii. Can a validated vote be included in the final tally? Requirement for "Accuracy".

iii. Can voters be verified to be who they claimed they are? Requirement for "Authenticity".

iv. Can the e-voting system developed on the framework permits only eligible voters to vote and only vote only once? Requirement for "Democracy".

v. Can the e-voting developed on the framework ensure that neither election authorities nor anyone else can link any ballot to the voter who cast it? Requirement for "Privacy".

vi. Can the e-voting developed on the framework ensure that no voter can prove that he or she voted in a particular way? Requirement for "Secrecy/non-coercion".

vii. Can the e-voting developed on the framework allow voters to independently verify that their votes have been counted correctly? Requirement for "Verifiability".

Also, the following questions bothering on social factors were raised in the questionnaire: 
i. Could e-voting system developed on the framework eliminate rigging and other problems associated with conventional voting systems?

ii. Could the e-voting framework enhance citizen participation in electioneering processes?

iii. Could the developed e-voting framework impel free, fair and credible e-elections?

\subsection{Study Population and Sample Size}

The study population comprises of users of acceptable voting age (18 years and above) who had at one time or the other participated in an electioneering process in Nigeria. This population is taken from students and staff of Department of Computer Science and Engineering, Ladoke Akintola University of Technology, Ogbomoso, Nigeria. A total of one hundred and fifty questionnaires were distributed for evaluation of the e-voting framework after experimental usage at the pre-voting, voting and postvoting phases for desired generic and functional requirements as well as social factors. Backend data and information were made able for post-voting evaluation of the e-voting model.

\subsection{Data Collection and Analysis}

Of the one hundred and fifty questionnaires that were administered, one hundred and twenty-six responses were received from respondents. Primary data from the dully filled questionnaires was captured, compiled, and analyzed using SPSS version 12 for Windows environment. Similar Likert items were grouped together to formulate four performance evaluation metrics which are System Security Index (SSI), System Degree of Relevance (SDR), System Reliability Index (SRI) and System Ease of Usage (SEU) in SPSS. Cronbach's alpha test was to test for the reliability analysis (internal consistency) for each of the grouped Likert items. These metrics were used to evaluate the performance of the e-voting framework. System Security Index (SSI) measures the degree to which the model fulfilled the security requirements of e-voting systems as defined by [5]; the same of which are the generic requirements defined in Section 2. The other three metrics measure other functional requirements and social factors. The users expressed their perception about the degree to which the developed e-voting framework fulfills the generic and functional requirements of voting systems as well as the social factors by using the following Likert response category of 1 to 5. Survey targets were set for each evaluation parameter of the developed e-voting framework; the intent of which is to give an objective evaluation of the adequacy of the system in providing a platform for the delivery of free, fair, transparent and credible e- election.

\section{RESULTS AND DISCUSSION}

Satisfying the generic requirements of privacy, accuracy, authenticity, integrity, democracy and verifiability form the basis of the quantitative evaluation of the performance of the e-voting model. After data capture and analysis from the administered questionnaire, the percentage of users that believe the e-voting model is capable of ensuring voters' privacy and authenticity is
$82.64 \%$ and $83.87 \%$ respectively. The percentage of users that submitted that the integrity, accuracy and verifiability of ballots casted can be guaranteed by the e-voting model is $82.25 \%, 81.45 \%$ and $81.96 \%$ respectively. $86.17 \%$ of users agreed that the model would not disfranchise any eligible voter and that all voters can only vote once. Over eighty percent $(88.70 \%)$ of users submitted that the voting model cannot allow rigging and other similar irregularities. $86.29 \%$ and $82.25 \%$ of users opined that the e-voting will enhance and increase citizens' participation and credibility of elections respectively, if implement for large scale elections. These analysis are depicted the bar chart representation of Figure 6.

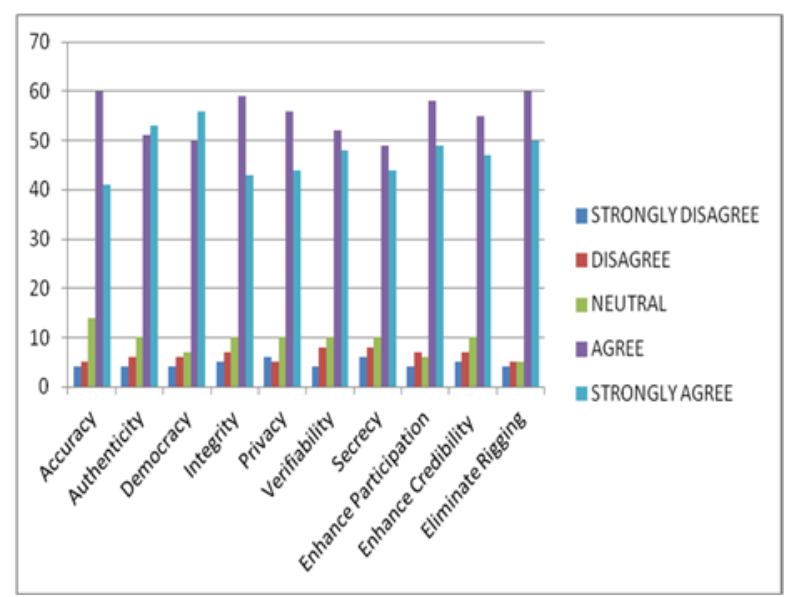

Fig. 6 Results of the Performance Evaluation of the Generic and Functional Requirements of a Multifaceted Voting Framework

Table 1 depicts the result of the Cronbach's alpha test carried out on the grouped Likert items for evaluating the e-voting model. Three of the groups, that is those evaluating requirements for security, reliability and relevance have Cronbach's alpha coefficient greater than 0.7 ; which is considered as "acceptable" following the rules of thumb of [5]. Only the requirement for low technical knowhow in using the e-voting falls short of the acceptable value.

Table 1 Reliability Test for Parameters used in Metric Formation

\begin{tabular}{ccc}
\hline $\begin{array}{c}\text { Groups } \\
\text { of } \\
\text { Likert } \\
\text { Items }\end{array}$ & $\begin{array}{c}\text { Cronbach's } \\
\text { alpha } \\
\text { coefficient }\end{array}$ & $\begin{array}{c}\text { (George and } \\
\text { Mallery, 2003) } \\
\text { Definition }\end{array}$ \\
\hline 1 & 0.7520 & Acceptable \\
2 & 0.7213 & Acceptable \\
3 & 0.6120 & Questionable \\
4 & 0.7322 & Acceptable \\
\hline
\end{tabular}

Table 2 shows the summary of the result of the performance evaluation metrics obtained for the e-voting model. The table shows that the users' rating of the model surpassed the set targets in all the four cases. This shows that the e-voting model can ensure voters' privacy and authenticity while the integrity, accuracy and verifiability of ballots casted are guaranteed. Also, this results shows 
that the model is relevant in the delivery of transparent, free, fair and credible elections. Users find the system relatively easy to use, as the technical knowhow requirement to use the system is considerably minimal. The users' assessment of the system for System Security Index, System Reliability Index (SRI) and System Degree of Relevance (SDR) is virtually equal while the System Ease of Usage (SEU) is the least rated. The low rating of the System Ease of Usage (SEU) may be due to computer literacy level, hardware requirements and other issues of digital divides associated with the internet voting option of the developed model. These factors were also considered before setting a lower response design target for this evaluation metric. Figure 7 depicts the graphically representation of the performance evaluation metrics.

Table 2 Summary of Result of Performance Evaluation Metrics

\begin{tabular}{lccc}
\hline $\begin{array}{l}\text { Performance } \\
\text { Evaluation } \\
\text { Metrics }\end{array}$ & $\begin{array}{c}\text { Response } \\
\text { Design } \\
\text { Target }\end{array}$ & $\begin{array}{c}\text { Number } \\
\text { of } \\
\text { Respons } \\
\text { espons }\end{array}$ & $\begin{array}{c}\text { Respons } \\
\text { Mean }\end{array}$ \\
\hline $\begin{array}{l}\text { System } \\
\text { Security } \\
\text { Index (SSI) }\end{array}$ & $>4$ & 126 & 4.13 \\
$\begin{array}{l}\text { System } \\
\text { Reliability }\end{array}$ & $>4$ & 126 & 4.08 \\
Index (SRI) & & & \\
$\begin{array}{l}\text { System Ease of } \\
\text { Usage (SEU) }\end{array}$ & $>3$ & 126 & 3.54 \\
$\begin{array}{l}\text { System Degree } \\
\text { of Relevance } \\
\text { (SDR) }\end{array}$ & $>4$ & 126 & 4.10 \\
\hline
\end{tabular}

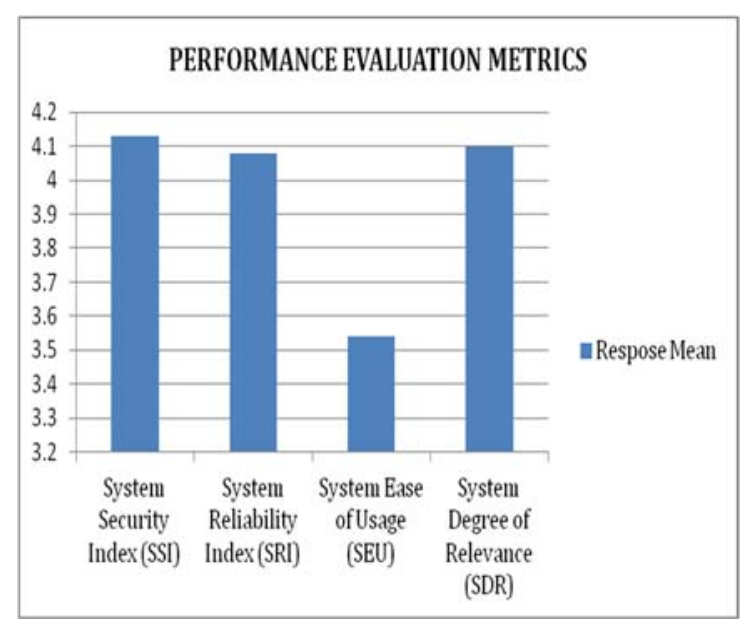

Fig. 7 Graphical Representation of the Results of the Performance Evaluation Metrics

\section{CONCLUSIONS}

This paper has detailed the architectural framework and performance evaluation of a multifaceted electronic voting model that could be used as a platform for a credible, free and fair e-election. The generic and functional requirements of electronic voting systems have been aptly elucidated by the contents of this work and can be used as a reference model by relevant stake holders when designing the requirements definition for e-voting systems. If implemented for large scale elections, the multifaceted evoting framework evaluated in this work will undoubtedly enabled voters to cast their vote from a place other than the poll site in their voting district, facilitate the casting of the vote by the voter, facilitate more participation in elections by those who are entitled to vote, widen access to the voting process for voters with disabilities or those having other difficulties in being physically present at a poll site, increased voters turnout by providing additional voting channels, reduced overall cost to the electoral authorities of conducting an election, deliver voting results reliably and more quickly amongst many other benefits.

\section{REFERENCES}

[1] CoE, (2003): "Council of Europe's Multidisciplinary Ad Hoc Group of Specialists on Legal, Operational and Technical Standards for E-enabled Voting (IP1-S$\mathrm{EE})$.

[2] CRANOR, L. F. - CYTRON, R. K. (1996): “Design and Implementation of a Practical Security-Conscious Electronic Polling System", Department of Computer Science, Washington University St. Louis, Technical Report, WUCS-96-02port.

[3] FISCHER, E. A., (2003): "Election Reform and Electronic Voting Systems (DREs): Analysis of Security Issues", Congressional Research Service, Library of Congress.

[4] FUJIOKA, A. - OKAMOTO, T. - OHTA, K. (1992): "A Practical Secret Voting Scheme for Large Scale Elections" Seberry J. and Zheng Y. editors, in Advances in Cryptology: AUSCRYPT '92, volume 718 of Lecture Notes in Computer Science, pages 244251, Springer Verlag Gold Coast, Queensland, Australia.

[5] GEORGE, D. - MALLERY, P. (2003): "SPSS for Windows step by step: A simple Guide and Reference. 11.0 update" (4th ed.), Boston: Allyn \& Bacon.

[6] IBRAHIM, S. - KAMAT, M. - SALLEH, M. ABDUL AZIZ, S. (2003): "Secure voting using blind signature“. Available at URL http://eprints. utm. my/3262/1/IEEE02-EVS_full_paper_ver14Nov.pdf

[7] LEBRE, R. - ZÚQUETE, A. - FERREIRA, P. (2004): "Internet Voting: Improving Resistance to Malicious Servers in REVS", IADIS International Conference on Applied Computing 2004, Lisbon, Portugal. 
[8] MALKAWI, M. - KHASAWNEH, M. - ALJARRAH, O. (2009): Modeling and Simulation of a Robust E-voting System. Communications of the IBIMA, Volume 8, 2009. ISSN: 1943-7765.

[9] MUIR, H. - LAVILLE, S. - GILLAN, A. (2005): "New Fears over Postal Vote Fraud", Accessed at http://politics.guardian.co.uk/election/story/0,15803,1 458341,00.html.

[10] NSF, (2001): "Report on the National Workshop on Internet Voting: Issues and Research Agenda", National Science Foundation, at http://news.findlaw.com/cnn/docs/voting/nsfe-vo terprt.pdf.

[11] OKEDIRAN, O. O. - OMIDIORA, E. O. OLABIYISI, S. O. - GANIYU, R. A. - ALO, O. O. (2011): "A Framework for a Multifaceted Electronic Voting System", International Journal of Applied Science and Technology, Philadelphia, USA, 1(4): 135-142.

[12] OKEDIRAN, O. O. - OMIDIORA, E. O. OLABIYISI, S. O. - GANIYU, R. A. (2012): "A Review of the Underlying Concepts of Electronic Voting", Journal of Information and Knowledge Management, International Institute of Science, Technology and Education, New York, USA, 2(1):821.

[13] OKEDIRAN, O. O. - GANIYU, R. A. (2015): “A Framework for Electronic Voting in Nigeria"
International Journal of Computer Applications, New York, United States, 129(3): 13-16.

[14] QADAH, G. Z., (2005): "Requirements, Design and Implementation of an E-voting System" Proceedings of IADIS International Conference on applied Computing, Algarve, Portugal, pp. 405-409.

Received March 19, 2019, accepted April 30, 2019

\section{BIOGRAPHY}

Oladotun O. Okediran is Senior Lecturer in the Department of Computer Science and Engineering, Ladoke Akintola University of Technology, Ogbomoso, Nigeria. He graduated with B. Tech. Computer Engineering and M.Tech. and Ph.D Computer Science from Ladoke Akintola University of Technology, Ogbomoso, Nigeria, in 2002, 2008 and 2011 respectively. He has published in reputable journals. His research interests include: Information Systems, Optimization, Modeling and Simulation of concurrent system, biometrics-based algorithms and their applications. He belongs to the following professional bodies: Full member, Computer Professionals (Registration) Council of Nigeria (MCPN); Registered Engineer, Council for the Regulation of Engineering in Nigeria (COREN). 